\title{
A perspectiva dos pais diante da gestação na adolescência*
}

\author{
Ana Cristina Garcia Dias ${ }^{l}$ \\ Naiana Dapieve Patias ${ }^{2}$ \\ Universidade Federal de Santa Maria \\ Marília Reginato Gabriel ${ }^{3}$ \\ Marco Antônio Pereira Teixeira ${ }^{4}$ \\ Universidade Federal do Rio Grande do Sul
}

\begin{abstract}
A família é considerada o primeiro e principal ambiente de desenvolvimento dos filhos. Durante a de gestação na adolescência ela pode servir como fonte de apoio ou de estresse para a gestante. O objetivo desse estudo foi descrever as percepções e sentimentos de pais de adolescentes gestantes atendidas em um hospital público de Porto Alegre - RS. Foram entrevistados nove mães e quatro pais com idades variando entre 33 e 55 anos, de diferentes estratos sócio econômicos da população (baixo e médio). Esses pais foram entrevistados através de um roteiro semiestruturado. As análises das entrevistas foram desenvolvidas através do enfoque fenomenológico. Os resultados indicam a multiplicidade de reações, percepções e sentimentos dos pais diante da notícia e da vivência da gestação das filhas adolescentes. Através do apoio parental (ou sua ausência), os pais influenciam na forma como as adolescentes vivenciam essa experiência, tendo um papel importante nesse processo.
\end{abstract}

Palavras-chave: Adolescência - Gestação -Família.
The family is considered the first and most important context of development for children. During adolescent pregnancy it may function as a source of stress or support for the pregnant adolescent. The aim of this study was to describe the perceptions and feelings of parents of pregnant adolescents attending a public hospital in Porto Alegre/RS. Nine mothers and four fathers, aged between 33 to 55 years, from low and middle socioeconomic status, were interviewed using a semi-structured interview guide. A phenomenological approach was used to analyze the data. Results show that parents experience a multiplicity of reactions, perceptions and feelings when they discover that their daughters are pregnant and have to deal with this experience. Through parental support (or its absence), parents influence the way adolescents experience pregnancy, playing an important role in this process.

Keywords: Adolescence - Pregnancy Family.

\footnotetext{
* The perspective of parents on teenage pregnancy

${ }^{1}$ Docente do Programa de Pós-Graduação em Psicologia, Universidade Federal de Santa Maria, Santa Maria, RS. Endereço para correspondências: Rua Floriano Peixoto 1750, Sala 308, Santa Maria, RS, 97015-372 (anacristinagarciadias@gmail.com).

${ }^{2}$ Aluna do Programa de Pós-Graduação em Psicologia, Universidade Federal de Santa Maria.

${ }^{3}$ Aluna do Programa de Pós-Graduação em Psicologia da Universidade Federal do Rio Grande do Sul.

${ }^{4}$ Docente do Programa de Pós-Graduação em Psicologia, Universidade Federal do Rio Grande do Sul.
} 


\title{
H UM ANAS
}

\section{Introdução}

\begin{abstract}
A adolescência é considerada por muitos autores um momento de tensão para o sistema familiar. As relações familiares se transformam com a chegada do filho na adolescência porque a definição de um novo status identitário para o jovem implica na redefinição dos papéis e das posições dos membros dentro do sistema familiar. A relação entre pais e filhos na adolescência é frequentemente entendida como uma relação conflituosa, tanto em função das novas necessidades apresentadas pelo adolescente como devido às novas exigências e adaptações existenciais experimentadas pelos pais, que podem estar vivenciado a "crise" da meia-idade (BOCK, 2007; CERVENY \& BERTHOUD, 2009; PRETO, 1995).

Cerveny e Berthoud (2009) sugerem que as dificuldades encontradas nas relações entre o jovem e seus pais podem ser decorrentes da sobreposição de crises presentes em cada etapa do desenvolvimento desses indivíduos, que ocorrem simultaneamente durante esse momento do ciclo vital e familiar. Considera-se que o "sistema familiar adolesce", ocorrendo um "alinhamento de crises evolutivas", que podem provocar crises na família. O jovem experimentaria uma série de transformações físicas, emocionais, cognitivas e sociais que lhe convocariam a reestruturar a sua identidade. Os pais, por sua vez, também poderiam estar em um momento de reestruturação da própria identidade, uma vez que, por se encontrarem na meia idade, estão vivenciando um processo de reavaliação de suas escolhas pessoais, nas diversas esferas de suas vidas.
\end{abstract}

Preto (1995) considera que mesmo que a metamorfose familiar nesse período possa despertar sentimentos de confusão e de perturbação nos momentos iniciais, posteriormente a maioria das famílias consegue se organizar e se adaptar às novas tarefas presentes nesse momento do ciclo vital e familiar. Essa reorganização de papéis e funções tanto dos indivíduos como do grupo familiar possibilita que a família entre em uma nova etapa e o adolescente realize sua passagem para o mundo adulto, buscando sua autonomia e independência.

Contudo, algumas situações, passíveis de ocorrer durante a adolescência, podem alterar o funcionamento familiar de uma forma mais marcante. Uma dessas situações diz respeito à gravidez na adolescência. Esse fenômeno é comumente considerado como um problema social e de saúde pública que gera diferentes consequiências biopsicossociais para a adolescente e sua família. O fenômeno é frequentemente associado a menores níveis de escolaridade, pobreza, subemprego, estresse, maus tratos infantis, problemas de saúde e ônus econômico para os serviços de saúde, entre outras consequiências tidas como adversas (CHALEM et al., 2007; FREITAS \& BOTEGA, 2002; GAMA et al., 2002; YAZLLE et al., 2002). Porém, esse fenômeno é 
complexo e multideterminado, podendo assumir diferentes significados para a adolescente e para sua família (DIAS \& TEIXEIRA, 2010). Para a jovem, a gestação pode significar tanto a realização de um sonho como a reformulação dos planos de vida em função da necessidade de assumir novos papéis (DIAS et al., 2011). Para os pais, essa experiência pode tanto revisar suas expectativas em relação ao futuro da filha, como representar a chegada de mais um membro na família, que trará renovação e alegria (SILVA \& TONETE, 2006).

Frequentemente, os estudos sobre gravidez e maternidade estão centrados nas experiências e significados da gravidez e maternidade a partir da perspectiva dos jovens que passam pela situação. Por outro lado, sabe-se que a família é considerada como o primeiro e o principal ambiente do desenvolvimento tanto de crianças, como adolescentes. No contexto da gestação e da maternidade, ela possui um papel importante, servindo como fonte de apoio ou de estresse para a gestante (LIMA et al., 2004; SILVA \& TONETE, 2006). Estudos têm demonstrado a importância da família no contexto da gravidez e da maternidade adolescentes. No entanto, esses estudos têm focado apenas na percepção ou reação ante a notícia da gestação (HOGA et al., 2009; HOGA et al., 2010) e no apoio ou não os adolescentes gestantes e/ou mães (HOGA et al., 2009), sendo pouco investigados, por exemplo, o que a família pensa a respeito da gestação e qual sua percepção sobre esses acontecimentos.

As ideias anteriormente apresentadas emergiram da realização de um levantamento de artigos publicados no portal scielo (www.scielo.br), que utilizavam os descritores: gravidez and adolescência. Inicialmente, foram identificados 205 artigos que se referem, em sua maioria, as percepção e vivências das adolescentes grávidas. Ao se buscar refinar a pesquisa utilizando os descritores: gravidez and adolescência and família identificou-se 38 trabalhos, sendo a maioria deles também realizada a partir da perspectiva dos adolescentes que estão passando pela situação da gravidez e/ou maternidade. O presente estudo busca ampliar a compreensão sobre o fenômeno da gestação na adolescência, a partir da investigação da percepção e vivência dos pais da menina gestante sobre o fenômeno. Neste estudo, a expressão "pais" será utilizada para referirse coletivamente ao conjunto de pais e mães; quando a referência for exclusiva aos pais homens, será usada a expressão "pais (homens)".

\section{Método}

\section{Participantes}

Foram informantes deste estudo nove mães e quatro pais (homens) de adolescentes grávidas, de um total de 10 adolescentes gestantes, que estavam 


\section{HUM ANAS}

sendo acompanhadas em um hospital público que atende preferencialmente população de classes baixa e média. Os pais tinham idades entre 33 e 55 anos e graus de escolaridade variados (desde o ensino fundamental incompleto até ensino médio completo). As famílias eram compostas por um ou ambos os genitores e os filhos, cujo número variava entre dois e cinco. Em cinco das famílias entrevistadas os pais encontravam-se separados, embora morando na mesma casa devido à ausência de recursos financeiros para viverem em casas separadas. Houve dois casos nos quais ocorreram mais de uma gestação na adolescência na família; em uma delas, inclusive, duas adolescentes encontravam-se gestando durante o período da pesquisa. Cabe ressaltar ainda que algumas das mães entrevistadas vivenciaram a situação de gestação na adolescência.

\section{Instrumento e procedimentos}

Foi utilizado um roteiro tópico para entrevista, abordando temas relacionados à gestação da filha, tais como percepções e sentimentos acerca do fenômeno. O contato inicial com os pais foi realizado através de um telefonema, após uma carta convite ter sido levada e entregue aos pais pelas gestantes, que eram atendidas ou frequientavam um curso de preparo ao parto em um hospital público do sul do país. Aos pais que demonstraram interesse em participar da pesquisa, foram detalhados os objetivos e procedimentos do estudo, a fim de que eles pudessem confirmar ou não a sua participação no mesmo. Algumas das entrevistas foram realizadas na instituição, em uma sala fornecida pelo serviço de Psicologia do Hospital, enquanto outras ocorreram na casa dos entrevistados. Não houve um padrão na realização das entrevistas com os pais, tendo algumas sido realizadas individualmente e outras com ambos os cônjuges.

As entrevistas com o casal foram realizadas sempre que, no início da entrevista domiciliar, os pais se apresentassem juntos para a mesma. Nesses casos, não foram requisitadas entrevistas individuais, pois a experiência decorrente das primeiras entrevistas realizadas mostrou que os pais (homens) tendiam a recusar o encontro individual com a entrevistadora. Sendo assim, optou-se por não desperdiçar a oportunidade de ouvir a opinião dos pais (homens) nesses encontros domiciliares, ainda que isso se constituísse em uma variação na forma de coletar os depoimentos. No início da entrevista, após uma nova explicação dos objetivos do estudo, foi entregue aos pais o Termo de Consentimento Livre e Esclarecido que garantia o sigilo e a confidencialidade das informações prestadas, bem como descrevia os riscos e benefícios de participação no estudo. O presente projeto de pesquisa foi aprovado pelo comitê de ética do hospital no qual a pesquisa foi realizada. Nomes fictícios são adotados na descrição das informações oferecidas pelos participantes. 


\section{Análise das entrevistas}

Optou-se por um delineamento fenomenológico uma vez que o objetivo do estudo foi compreender a perspectiva e experiência dos pais frente à gravidez da filha adolescente. Foram seguidos os passos sugeridos por Ablamowicz (1992), descritos a seguir: 1) descrição fenomenológica: organização das entrevistas, revisão e identificação dos temas relacionados à experiência que aparecem nos relatos, transcrição dos relatos relevantes ao problema da pesquisa; 2) redução fenomenológica: registro das expressões relevantes e agrupamento em categorias conforme os temas, reflexão sobre os temas para descoberta de inter-relações referentes ao objeto da pesquisa; 3 ) interpretação fenomenológica: avaliação dos temas emergentes para chegar a uma descrição fundamental, interpretação do fenômeno estudado contrastando a perspectiva das informantes com a literatura estudada.

\section{Descrição fenomenológica}

Inicialmente as entrevistas foram transcritas em sua íntegra. Após leituras sucessivas dos relatos buscou-se realizar uma síntese descritiva de cada um dos relatos, preservando apenas as partes consideradas essenciais à compreensão do fenômeno. Descartou-se nessa síntese todo material que não estava diretamente associado aos objetivos do trabalho. Essa separação entre os dados essenciais e não essenciais para o conhecimento do fenômeno foi realizada de maneira intuitiva e experiencial. A descrição buscou preservar a ordem cronológica em que os temas emergiram na entrevista, além de frases revelatórias relacionadas ao fenômeno. A fim de exemplificar o tema, foram selecionadas vinhetas para algumas das descrições. No entanto, a análise foi realizada com base no conjunto integral de relatos dos participantes para cada categoria.

\section{Resultados e discussão - redução e interpretação fenomenológicas}

O objetivo da redução é refinar a descrição fenomenológica. Nela buscase oferecer um mapeamento das diversas possibilidades presentes nas experiências das informantes, através de unidades temáticas, suspendendo os pré-conceitos e teorias prévias sobre o fenômeno. Nesse estudo, a redução apresentase como uma nova descrição (para o leitor) dos casos agrupados em categorias temáticas, a saber: 1) Aborto: Uma alternativa; 2) Porque a filha engravidou? De quem é a culpa?; 3) Papel de avô/avó ou papel de mãe/pai; 4) O pai do neto e 5) A relação da filha com o rapaz: Como fica? 


\section{HUMANAS}

Ao final de cada categoria é estabelecida uma discussão entre os dados empíricos obtidos no estudo e a literatura pesquisada sobre os temas emergentes dos depoimentos (interpretação).

a) Aborto: uma alternativa?

Houve pais que disseram que sempre foram contra a realização do aborto. Outros cogitaram essa hipótese inicialmente; contudo, a descartaram após refletirem melhor sobre a situação ou, então, avaliarem os riscos que a filha correria se realizasse o mesmo. Em alguns casos foi observada a pressão da família ou mesmo de amigos e vizinhos para a realização do aborto. Algumas famílias chegaram a buscar profissionais de saúde para decidirem a atitude a ser adotada.

[...] A minha irmã é que meio que pressionou. "Não, porque ela tem que tirar. Porque não sei o que... porque ela não tem condições"... Ela chegou e disse assim pra ela: "Simone isso aí foi uma porra que grudou no teu ovário, tira sem problema nenhum. Tu não vai ter condições de manter, nem emocional, nem financeira" (Maria, 36 anos, filha 16 anos). A primeira reação dele (pai). "Vão fazer um aborto, porque tu não pode ter esse filho, porque tu é muito nova. Tu já pensou, tu vai perder toda a tua juventude, o teu estudo, teu sonho que tu tinha de viajar, de fazer tantas coisas que tu queria fazer"... A psicóloga disse que podia, que a gente tinha direito de escolher, de levar ela numa clínica ou não (Maristela, 42 anos, filha 12 anos).

Alguns pais deixaram para a filha decidir se esta desejaria manter a gestação ou não; outros tomaram a decisão pela menina. Observou-se que a opinião e o apoio da família foram fatores relevantes considerados no prosseguimento ou não da gestação pela menina, segundo o depoimento desses pais. Os pais, ao considerarem o aborto, pensaram no prosseguimento de um projeto de vida das filhas, que era percebido como interrompido pela gestação. Em algumas situações, o aborto não podia ser mais realizado, pois devido ao tempo de gestação apresentaria risco de morte para a menina. Outro fator que contribuiu para a não efetivação de aborto foi a realização de ecografia(s): esse exame pareceu influenciar a decisão pela continuidade da gestação, tanto para os pais como para as meninas, uma vez que nesses casos o bebê tornou-se mais concreto para os envolvidos. 
A perspectiva dos pais diante da gestação na adolescência A.C.G. Dias, N.D. Patias, M.R. Gabriel \& M.A.P. Teixeira

\begin{abstract}
Aí fui e comprei os remédios, fiquei com os remédios na minha bolsa. Aí quando eu comprei os remédios que eu ia dar pra ela. "Ah, eu não vou ter coragem de fazer isso, de dar pra ela. Se acontece algum problema? Eu não vou assumir esse risco que pode até não dar nada, mas pode acontecer de dar"... Até que quando eu cheguei pra ela e disse: "Simone pensa bem, tu vai decidir, tu quer ou não quer?". Daí ela realmente decidiu: "Não, eu quero". "Então, ponto final, ninguém vai te obrigar a fazer isso" (Maria, 36 anos, filha 16 anos).

(Vocês pensavam em fazer aborto?)... Num primeiro momento eu até que consenti, concordei com ela. E me informei a respeito e tal... Por ter já 12 semanas, porque na minha cabeça era uma coisa muito recente, de três, quatro semanas da minha descoberta, da minha desconfiança... E na verdade não era. Eu chorei muito, e eu me questionei muito, e eu me perguntei muito... com 12 semanas era inadmissível, não era possível, primeiro porque eu tava ali vendo o bebezinho e o coraçãozinho e tudo mais (Márcia, 40 anos, filha 15 anos).
\end{abstract}

A possibilidade de efetuar um aborto foi cogitada no início da gravidez, sendo percebida como uma solução para o problema nas situações de gestação indesejada. Apesar do estudo não buscar trabalhar com prevalência de situações de aborto, é importante destacar que todas as famílias relataram pensar sobre essa possibilidade, algumas descrevendo que não o realizaram apenas em função do tempo de gravidez. Outras famílias descreveram que refletir sobre as consequiências físicas e psíquicas envolvidas na realização do aborto contribuiu para não realização do mesmo.

Silva e Salomão (2003) revelaram que 16\% das mães de adolescentes grávidas buscaram induzir a filha a abortar o bebê. No entanto, apenas metade dessas avós que sugeriram a realização do aborto conseguiu que as jovens realizassem o aborto, uma vez que a própria adolescente ou outros familiares não aceitaram essa opção. Assim, percebe-se a importância de orientar as pessoas com as quais a jovem divide a notícia da gestação, pois as mesmas influenciam diretamente na decisão do prosseguimento ou não da gestação, a partir do apoio oferecido (ou não) à gestante (PERES \& HEIBORN, 2006).

Boemer e Mariutti (2003) observam que o aborto, espontâneo ou provocado, é uma situação delicada e sofrida, pois envolve muitos medos, tabus, preconceitos, discriminações e culpa. De acordo com Correia e Colaboradores (2011), 


\section{HUM AN AS}

as razões que levam ao aborto geralmente estão associadas ao modo como a cultura e a sociedade encaram a sexualidade dos jovens, que usualmente é vista como um tema proibido ou sobre o qual não se deve falar. Assim, torna-se difícil para um adolescente conversar sobre sua sexualidade com seus pais e mesmo com outras pessoas. Então, ao perceber-se grávida, a jovem pode, por medo dos pais ou da opinião de outras pessoas, acabar optando pelo aborto, mesmo que isso possa gerar sentimentos ambivalentes.

Em função disso, ressalta-se a importância de se refletir e desenvolver intervenções junto a adolescentes e famílias sobre o tema, uma vez que essa situação pode estar associada ao fenômeno da gravidez adolescente. As informações descritas nesse estudo se referem apenas àquelas famílias nas quais as filhas prosseguiram com a gestação e se dispuseram a compartilhar suas experiências. Cabe aos pais, escola e profissionais da saúde orientar os jovens acerca da sexualidade e de uma gestação nesse período de vida, prevenindo gestações indesejadas e, conseqüentemente, o abortamento. Os profissionais da saúde devem orientar pais acerca da melhor forma de conversar com os filhos acerca da prevenção da gestação e também das doenças sexualmente transmissíveis. Esses aspectos são propostos, por exemplo, no programa saúde do adolescente (PROSAD), do governo federal (BRASIL, 1996).

b) Por que a filha engravidou? De quem é a culpa?

Os pais descreveram que não se conformavam com a gestação da filha, relatando que em muitos momentos buscaram achar um culpado para essa situação considerada problemática. Seus sentimentos foram descritos como ambíguos, pois ao mesmo tempo em que buscavam achar outro culpado, eles próprios se consideravam culpados pela situação, uma vez que a gestação foi percebida como um descuido na educação e atenção dispensada à filha. De fato, o sentimento de culpa esteve associado aos sentimentos de impotência e fracasso face à educação da(s) filha(s). Por outro lado, os pais também atribuíram culpa tanto à(s) filha(s) como aos rapazes de quem as filhas engravidaram. As filhas foram consideradas culpadas por não seguirem as recomendações sobre métodos contraceptivos que os pais teriam passado, juntamente com alertas sobre os riscos do exercício da sexualidade. Já os rapazes foram também apontados como culpados por abusarem dos benefícios concedidos e da confiança depositada neles.

Aquela coisa, a culpa foi minha porque eu realmente não cuidei. Mas às vezes tu não tens, mas o que eu ia fazer?... Às vezes, eu fico meio culpada, 


\section{A perspectiva dos pais diante da gestação na adolescência}

A.C.G. Dias, N.D. Patias, M.R. Gabriel \& M.A.P. Teixeira

mas eu não vou me culpar, porque eu avisei. Eu conversei com ela... Eu devia realmente ter cuidado melhor. Não tinha como, só se eu trancasse (Mariana, 33 anos, filha 14 anos).

Observa-se que quando os pais culpam a adolescente, seus depoimentos são marcados por expressões que buscam lhes eximir de uma possível responsabilidade pela gravidez, sendo ressaltados os conselhos de alerta oferecidos por eles às filhas. A idade da filha, a informação oferecida à mesma, a escolaridade da adolescente e o tipo de relacionamento que a menina mantinha com o rapaz foram fatores considerados pelos pais nesse processo de culpabilização de alguém pela ocorrência do fenômeno. Já quando os pais (homens) culpavam o rapaz, eles ressaltavam que o mesmo havia traído a confiança nele depositada, relatando que ofereciam privilégios ao jovem casal que eles, pais, não tiveram em sua juventude.

Porque aí, quando aparece um problema com o filho o quê que tu faz? Ou tu te culpa ou no caso um fica culpando o outro. No nosso caso ele ficou... eu fiquei culpando ele, de algumas coisas que tinham acontecido (Maria, 36 anos, filha 16 anos).

A culpa é deles mesmos. Se tem algum culpado, é ela mesmo que quis. Que é aquele caso quando um não quer, dois não fazem. Então se ela tivesse se preservado mais, conversado com ele, pensado em outras coisas. Até mesmo se ela tivesse me ouvido... O pai ficou furioso. Botou todas as culpas em mim... O meu pai era assim: tudo que podia acontecer assim dentro de casa, a culpada era a mãe (Mariana, 33 anos, filha 14 anos).

A atribuição de culpa esteve, em alguns casos, associada eminentemente à figura feminina, uma vez que a mãe é vista como a principal responsável pela educação da filha e a adolescente responsável pelo cuidado com seu corpo, contracepção e moral. Ainda nessa tentativa de encontrar quem seria o culpado, os pais referem que a família extensa (avós, tios) lhes responsabiliza pela situação da jovem, confirmando suas percepções que os mesmos falharam na educação dos filhos. Entre o casal de pais podem ser observadas tanto a atribuição de culpa exclusiva ao parceiro como o compartilhamento da culpa.

Porque a Patrícia (primeira filha a engravidar) sabia o que tava fazendo, sabia as consequiências, sabia a forma assim de evitar. Ou assim, as consequiências da situação dela com um amigo, que seria só um amigo, que não teria nenhum compromisso com ela... 
E da Fabiane não, já acho que foi assim... que foi um acidente que aconteceu, porque ela esqueceu da camisinha. É mesmo pela idade também a gente desculpa muitas coisas sabe. Ele (pai da adolescente) dizia que a culpa era minha, porque eu como mãe não podia deixar que aquilo acontecesse com uma filha (Maristela, 42 anos, filha 12 anos).

Por outro lado, a gestação pode não ter um culpado e ser atribuída a uma "vontade de Deus". Nessa situação a gestação encontra-se claramente associada ao desejo dessa avó voltar a ser mãe.

Ela engravidou porque... Deus quis. Tinha que ter um bebezinho na nossa família, de certo. Eu te confesso que eu queria muito esse neném... Assim, existem mais coisas entre o céu e a terra (Márcia, 40 anos, filha 15 anos).

As experiências que caracterizam essa categoria também foram descritas por outros autores (LIMA et al., 2004; SILVA \& TONETE, 2006). Esses estudos indicam que os pais sentem que falharam na educação da filha, sentindo-se impotentes face à ocorrência da gestação. Eles argumentam que fizeram tudo o que estava ao seu alcance para evitar a situação, oferecendo informações sobre prevenção para as filhas. Descrevem sentimentos de raiva e atribuem a responsabilidade à menina, que deveria ser a principal responsável pela realização da contracepção. Por outro lado, acreditam que erraram em algum ponto na educação das filhas, sentindo-se culpados e frustrados.

Percebe-se nos depoimentos que os pais (homens), mas principalmente as mães, sentem-se culpadas e frustradas pela gestação da filha. Isso se deve ao fato de que, ainda, a mulher é considerada a principal responsável pela educação dos filhos. Quando algo dá errado, a culpa é da mãe. Além disso, essa responsabilização da mulher também é percebida através do depoimento da mãe Estela, que culpa a filha pela gravidez. De fato, apesar das modificações nos papéis femininos e masculinos, ainda a principal responsável pela gravidez e posterior atividades decorrentes da maternidade, é a mulher (BORSA \& NUNES, 2011; WAGNER et al., 2005).

c) Papel da avó/avô versus papel da mãe/pai

Os avôs e avós podem se colocar no papel de pais da criança, justificando que são eles que irão assumir as despesas e responsabilidades pela filha e seu bebê. 
Algumas avós inclusive revelaram o desejo por ter uma nova criança na família. Em um caso deste estudo, os pais afirmaram que pretendiam assumir integralmente o bebê da filha, inclusive registrando-o como seu filho. Nessa situação a gestação da filha promoveu ainda mais a união dos pais da gestante, uma vez que os mesmos se mobilizaram para oferecer apoio à filha. Nesses casos, nos quais pais indicaram assumir inteiramente o bebê fruto da gestação da filha, isso se deu em função da necessidade de oferecer à filha a oportunidade de manter o projeto de vida (estudo, viagens) idealizado antes da gestação.

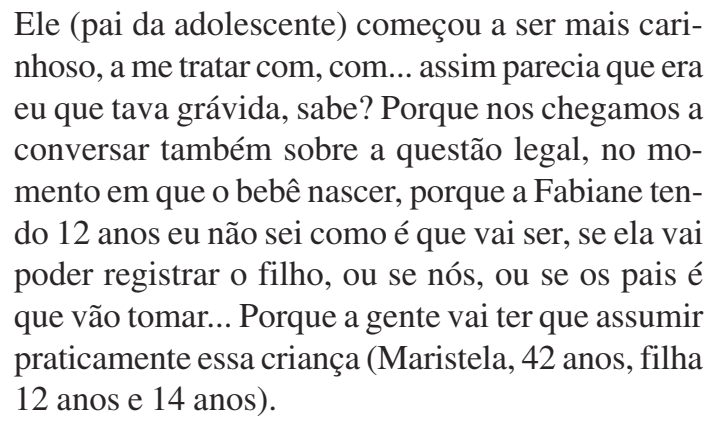

Outros pais, por sua vez, mostraram-se preocupados em delimitar claramente seus papéis de avós junto às filhas e netos, procurando reservar à filha o papel de mãe. No entanto, reconheceram que essa é uma tarefa difícil. De fato, percebeu-se que as mães estavam procurando preparar as filhas, alertando-as desde o momento da gestação, para as responsabilidades futuras que as mesmas teriam. Elas demonstraram preocupação com o futuro das filhas, especialmente porque esperavam que as jovens conseguissem conjugar os cuidados da criança com os estudos ou eventuais empregos que pudessem vir a ter. Nesse sentido, observou-se nos depoimentos dos pais que as intervenções dos profissionais de saúde, através de grupos de apoio à gestante e à família durante a gestação são importantes, uma vez que propiciam um espaço para reflexão e discussão dessas questões.

Eu to só colocando pra ela que vai ser uma responsabilidade grande que ela vai ter. Que eu vou procurar ser vó, não mãe. Porque até ela me colocou assim, que no grupo (de gestantes) que ela tá participando... porque eu vou procurar me policiar ao máximo pra não ser a mãe, e sim a avó. Embora eu sei que vai ser difícil, que a gente vai querer (Maria, 36 anos, filha 16 anos). 


\section{H UM ANAS}

Falcão e Salomão (2005) indicam que os avôs que assumem a responsabilidade pelo cuidado da criança o fazem por não sentir confiança na maturidade da filha adolescente para essa tarefa. Este sentimento faz com que esses avôs acabem restringindo as atividades da jovem mãe, impossibilitando que a mesma exerça o seu papel de modo pleno. Nesses casos, a avó se torna a mãe substituta do neto, exercendo diferentes atividades que vão desde cuidar da criança até apoiar a própria filha adolescente. Em algumas situações a avó chega a ser chamada de mãe pelo neto.

A decisão, porte parte dos pais, de assumir tarefas e responsabilidades que seriam das jovens tem por objetivo permitir que as filhas possam ter oportunidades e experiências semelhantes a outras adolescentes que não têm filhos. No entanto, essa situação pode gerar confusão de papéis e problemas no desenvolvimento, tanto da jovem como da criança. As adolescentes que moram e compartilham os cuidados com suas mães podem apresentar menores níveis de responsabilidade, maiores níveis de estresse e dificuldades em desempenhar seu papel materno (FONSECA, 2000); a criança pode sofrer maus tratos (BLACK et al., 2002) e apresentar problemas de comportamento (LEVANDOWSKI et al., 2008); e a avó pode desenvolver sintomas de depressão, especialmente se for mais jovem (KNOPLICH \& GUIMARÃES, 1999). Por outro lado, Unger e Cooley (1992) encontraram que as jovens que moram com as avós são mais propensas a retornarem aos estudos e alcançarem uma melhor renda do que aquelas que moram sozinhas ou com o companheiro. A respeito disso, alguns estudos mostram que, de fato, o apoio da família na situação de gravidez adolescente é importante, e varia tanto na intensidade, quanto na forma como o mesmo é fornecido. Em alguns casos, a família mobiliza-se para oferecer uma verdadeira rede de ajuda, sendo observados revezamentos entre os membros femininos da família (mãe, sogra, irmãs e adolescente) para o cuidado com a criança; há situações inclusive que irmãos da jovem mãe podem começar a trabalhar para ajudar no sustento do bebê (HOGA et al., 2009).

d) Percepções e reações relativas ao pai da criança

Os pais das adolescentes demonstraram diferentes percepções e atitudes frente ao pai da criança. Alguns perceberam o rapaz de maneira positiva, acreditando que futuramente este poderia ser um bom pai para a criança, uma vez que ele se mostrava preocupado e comprometido com a gestação da adolescente. Outros pais, especialmente os pais (homens) mostraram-se preocupados quanto à participação desse futuro pai na vida da filha e do neto. Tanto na primeira como na segunda situação, observou-se que os pais procuraram o rapaz para conversar sobre as providências a serem tomadas em função da gestação e, em alguns casos, possível união do jovem casal. 
Alguns pais relataram que desejavam manter uma boa relação com o rapaz, independente de este permanecer ou não casado com sua filha, pois lembravam que esse era o pai de seu neto(a).

As mães das adolescentes, especialmente, por considerarem que o período da gestação é um momento delicado para a mulher, esperavam que o rapaz apoiasse a filha durante esse período. Nesse sentido, foram relatadas preocupações tanto em termos financeiros como afetivos, sendo que essas preocupações estavam relacionadas tanto à união do casal quanto ao papel que o rapaz assumiria no cuidado e educação do filho(a).

\begin{abstract}
Mas ele é um amor de guri... Tomara que... eu peço a Deus que ele continue sendo assim como ele é. Mesmo que um dia eles não vão ficar juntos, não case... porque daí eu acho que ele vai ser um bom pai (Marcela, 49 anos, filha 19 anos).

Eu não sei se ele tem realmente algum sentimento por ela, se ele tiver... Ele que assuma isso aí, e que viva numa boa essa gravidez, que dê tranqüilidade pra ela, pra ela passar uma gravidez tranqüila (Marilene, 43 anos, filha 17 anos).
\end{abstract}

Alguns pais percebiam a relação da filha com o rapaz como problemática, pois tinham conhecimento de que o rapaz havia tido problemas com drogas, ou que a relação entre o jovem casal era difícil (com muitas brigas). Nesses casos, relataram preocupação em proteger a filha e o bebê do rapaz, que consideravam como perigoso. Há pais inclusive que afirmaram não querer que a filha registrasse seu filho(a) com o nome do jovem pai da criança. Esses pais acreditavam que desta forma o rapaz não teria poder algum sobre a criança. De modo geral, foi observado, através dos relatos, que esses pais faziam diferentes cobranças ao rapaz, quando este parecia não corresponder às expectativas desses pais. Um pai relatou que ativamente buscou afastar o jovem pai efetivamente do convívio com a filha e com o(a) futuro(a) neto(a).

Ele (pai do bebê) não reconhecendo a criança, ou não reconhecendo, mas registrando a criança, ele não vai conviver com essa criança. E se porventura, que ela é uma menina nova, de conhecer alguém, dessa pessoa ficar com ela e queira registrar essa criança, aí tem toda uma implicação burocrática, porque essa criança já é registrada e tem um pai. Se essa criança no registro não tiver o nome do pai, essa pessoa que for ficar com ela, e quiser assumir a criança com certeza assumirá (Marcelo, 36 anos, filha 15 anos). 


\section{HUMANAS}

A partir desses resultados, observa-se que parte dos pais das adolescentes percebe a participação do pai do neto como importante para a gestação e para a filha. Para Gonçalves, Parada e Bertoncello (2001), as jovens mães e suas famílias valorizam a participação do rapaz pelo apoio emocional oferecido. Inclusive, no mesmo estudo citado, algumas jovens indicaram que compreendem quando o rapaz não lhes apóia financeiramente, em função de dificuldades financeiras; contudo, não compreendem ou aceitam quando a falta de apoio é em nível emocional. Nesse sentido, qualquer movimentação paterna em termos financeiros ou de ajuda com o bebê pode ser reconhecida como um favor que o rapaz faz para a jovem mãe e para sua família (GODINHO et al., 2000).

Os pais das jovens, ao desejarem que os jovens pais ofereçam um apoio afetivo e financeiro às filhas, reconhecem que a experiência de gestação e maternidade implica em uma série de transformações que são fatores de estresse para a jovem. Bloom (1998) observa que um relacionamento satisfatório entre a adolescente grávida e o pai do bebê se reflete positivamente no comportamento afetivo da mãe com a criança. Essa autora indica que a recusa no reconhecimento da paternidade e a falta de suporte paterno podem ser uma fonte de estresse adicional, que pode prejudicar o vínculo da gestante com o filho, uma vez que provoca uma sobrecarga emocional e afetiva.

Com isso, percebe-se que a apreensão dos pais da adolescente com o envolvimento saudável do pai do bebê revela a preocupação com o tipo de apoio que a filha e o neto receberão. Tanto o apoio do pai do bebê como da família da adolescente são essenciais para a adaptação da jovem à maternidade (HOGA et al., 2009). Há uma relação positiva entre estes tipos de apoio e a satisfação com a maternidade, além de afetar na relação da futura mãe com o bebê, sendo que as mães que são apoiadas são menos punitivas ou rejeitadoras com seus filhos (ARCANJO et al., 2007; HOGA et al., 2010; LIMA et al., 2004).

\section{e) Relação da filha com o rapaz: como fica?}

De fato, observou-se que os pais demonstraram preocupação com a relação da filha e o pai da criança, especialmente, buscando definir qual seria o status da relação entre o jovem casal e a contribuição e/ou interferência do rapaz na criação do futuro neto. Percebe-se que a relação de namoro, como era anteriormente desenvolvida pelo jovem casal, é interditada. Como indicado anteriormente, a ocorrência da gravidez pode ser significada pelos pais como um abuso da liberdade concedida ao jovem casal. Assim, a gestação, para alguns pais, representa uma traição do rapaz que não respeitou sua filha e família. Além disso, o namoro é compreendido como um momento no qual o jovem casal está se conhecendo e não possui muitas responsabilidades. 


\title{
A perspectiva dos pais diante da gestação na adolescência
}

Por sua vez, a gestação, ao delimitar novas responsabilidades, faz com que esse período seja interrompido ou redefinido, uma vez que novos arranjos devem ser estabelecidos em função do nascimento da criança.

Os pais cobram da menina uma atitude do rapaz, e a elas cabe decidir se terminarão o relacionamento de namoro ou se manterão uma relação considerada mais duradoura e estável com o pai da criança, como casamento ou união consensual (morar junto). Alguns pais demonstraram preocupações em estabelecer as diretrizes para a vida futura da filha, tanto em termos afetivos, como em termos de projetos futuros escolares e laborais. Percebe-se também que ao definirem as responsabilidades do rapaz, esses pais buscam também definir as suas próprias responsabilidades face à criança, à filha e ao rapaz.

\begin{abstract}
Eu quero ver se eles vão dar certo juntos, já que eles têm um filho, entendeu?... Mas como é que fica a situação deles?... Como fica a situação deles pra eles namorarem? Vão ir aonde?... Se ela resolver que é com ele que ela quer casar, que ela vai ter o resto da vida em comum com ele, então que ela se decida por isso. Então eu queria uma coisa mais definida pra eles. Claro, que por eles serem muito novos (Mariana, 33 anos, filha 14 anos).
\end{abstract}

Além disso, alguns pais demonstraram preocupação em não facilitar o estabelecimento de uma vida sexual ativa para o casal, sem que seja estabelecido uma união mais estável entre o jovem casal. Apesar da gestação, parece que os pais ainda sentem dificuldades ou não admitem o exercício da sexualidade de suas filhas, considerando que a mesma deve ser regulada, especialmente no caso desta permanecer desacompanhada. De fato, observamos que os pais das adolescentes grávidas apresentam depoimentos ambíguos que refletem suas ansiedades face à situação do jovem casal: ao mesmo tempo em que dizem que querem que a filha escolha se deseja ou não permanecer com o rapaz, pressionam para que ocorra uma união ou separação da filha com o rapaz (pai da criança).

\footnotetext{
Não vou correr ela de casa mesmo que ela não case, mesmo que ela não tenha esse prazer de casar com o Tiago. Nós estamos tentando levar pra esse fim. Pra esse, pro casamento. Nós damos bem com a família dele, o pai dele é meu colega (Marcela, 49 anos, filha 19 anos).
}

O casamento civil pode ser uma exigência realizada por alguns pais, que lembram que uma união consensual pode ser dissolvida mais facilmente. 


\title{
HUM AN AS
}

Parece que o casamento é visto como um ritual que, de certa forma, visa "corrigir" um desvio de "rota" realizado pela filha. Ou seja, alguns pais parecem buscar no casamento um retorno a certa "ordem" natural da vida da filha, uma vez que a gestação parece assinalar que a jovem saiu do script esperado para mesma. Por outro lado, os pais podem ser radicalmente contra o casamento da filha com o rapaz, pois o consideram inadequado para a filha ou desejam que a menina tenha as mesmas oportunidades de vida (escolarização e profissionalização) que outras adolescentes de sua idade.

\begin{abstract}
Ah, ela queria casar, mas aí não pode casar por causa da idade... Aí resolveram ficar junto. Daí ficou um mês e pouco pra pensar melhor, deixar as coisas acalmar e já que não podia casar e queria ficar junto, a família dele e nós resolvemos então que fiquem (Marúcia, 40 anos, filhas 14 anos e 15 anos).

Essa paixão é muito imatura para ela durar muito tempo. Ela não tem consistência pra durar. Se ela quisesse ter casado, eu com certeza eu ia tentar dissuadi-la de todo maneira pra não casar... Esse não deixar é muito radical (Marcelo, 36 anos, filha 16 anos).
\end{abstract}

Observa-se que na concepção de alguns pais a atividade sexual ainda está vinculada à idéia de casamento e de responsabilidades presentes na vida adulta. Uma mãe observou que já que sua filha mantinha uma vida sexual ativa deveria pensar na possibilidade de casamento.

Comentário da mãe sobre a filha se achar muito nova para casar: que interessante, como é que tu podes pensar assim? E partiste pra um passo tão sério? Tudo bem falhou a pílula, mas desde uma vez que tu prática sexo, tu sabe que a qualquer momento tu corre esse risco (Marilene, 43 anos, filha 17 anos).

Foi interessante observar que entre os pais entrevistados foi mais cogitada a possibilidade da jovem ir morar na casa do rapaz do que o rapaz vir morar junto à família da adolescente gestante. Contudo, essa hipótese era descartada pela adolescente devido às suas previsões de possibilidades de atrito com os sogros. A decisão de permanecer solteira na casa paterna foi apoiada por alguns pais. Esses pais acreditavam que essa era a melhor solução, até que os jovens pudessem ter condições de se casarem. Mas alguns pais acreditavam que o casamento deveria ocorrer imediatamente, sendo a melhor solução para uma situação que foge ao script esperado para um adolescente. 


\title{
A perspectiva dos pais diante da gestação na adolescência
}

Percebeu-se também que a mãe da adolescente podia concordar com a decisão da filha de não casar, em função de sua própria experiência matrimonial, enquanto o pai (homem) almejava o casamento para a filha.

Como eu digo: "não adianta casar, e ficar um aqui e outro lá. Enquanto vocês não tiverem condições de manter um apartamento de vocês, tu fica aqui, e ele fica lá". Então eu acho que no fundo ele (marido) acha que as coisas não aconteceram como deveriam ter acontecido assim, o preto no branco por causa minha (Marilene, 43 anos, filha 17 anos).

Na representação desses pais, assumir a gestação está associado à responsabilidade. Uma mãe indica que, para ela, o rapaz assumir a gestação da filha significa que a filha deve ir morar com ele, e que o mesmo deve se responsabilizar financeiramente por sua filha.

\begin{abstract}
Ela tem medo de ir morar com ele. Mas eu digo: "Ela teria que tentar". Porque todo mundo pergunta se ele assumiu. Eu digo: "Ele assumiu". Mas ele não tá morando com ela, então como é que ele assumiu? "Ah, ele assumiu a responsabilidade sobre a criança, que ele vai ter". Então ele não assumiu ela (Mariana, 33 anos, filha 14 anos).
\end{abstract}

Alguns pais apresentaram também uma preocupação com o status civil das filhas, apesar de alguns estudos apontarem que apenas uma minoria de adolescentes que engravidam não tem companheiro (GODINHO et al., 2000; ESTEVES \& MENANDRO, 2005; MADI et al., 2001). Nossas informações, como aquelas encontradas no estudo de Silva e Tonete (2006), indicam que os pais apresentam expectativas a respeito dos papéis a serem desempenhados pela adolescente e pelo rapaz tanto em relação à criança como em relação à sociedade em geral. Isso parece ser importante para organização dos mesmos para que esses possam considerar que tipo de apoio será disponibilizado à gestante.

Steinberg e Silk (2002) lembram que a gestação na adolescência só começou a ser vista como um problema de saúde pública quando ela passou a ocorrer fora do casamento. Até meados da década de 50, o fenômeno não era problematizado, pois a maternidade adolescente ocorria na situação de matrimônio; assim, possíveis implicações econômicas e sociais estavam resolvidas ou tornavam-se menos aparentes. A partir da década de 60 observou-se o surgimento de novos padrões de comportamentos sexuais, que permitiram que o sexo fosse desvinculado da função reprodutiva, em função da invenção do contraceptivo oral. 


\section{HUMANAS}

No entanto, essa nova "liberdade sexual" não foi necessariamente acompanhada de transformações nos valores associados ao corpo, à sexualidade e aos papéis sexuais e de gênero presentes na sociedade. Hoje se percebe uma ambigüidade nos valores sociais referentes ao corpo, sexualidade e gênero que contribuem para o não uso de contraceptivos. Dessa forma, por trás da aparente liberdade, encontra-se, muitas vezes, uma moralidade rígida e proibitiva, especialmente no que diz respeito à sexualidade feminina. De fato, observa-se uma ambigüidade de mensagens em relação ao corpo e à sexualidade que também contribuem para a ausência de comportamento contraceptivo, já que fazer uso de contracepção é assumir-se como mulher/homem independente, exercendo sua sexualidade sem preconceitos e tabus, o que nem sempre é aceito socialmente (DIAS \& TEIXEIRA, 2010).

\section{Considerações finais}

O fenômeno da gravidez na adolescência é complexo, e pode ser visto através de diferentes perspectivas. A percepção dos pais da adolescente sobre o fenômeno coloca em foco alguns aspectos dessa experiência que são importantes para melhor compreender o modo como jovens gestantes e suas famílias lidam com a gestação, especialmente por parte de profissionais que trabalham com essa questão. Através dos depoimentos foi possível observar que a gestação da filha suscita diferentes sentimentos e preocupações nos pais. Percebese que a partir do recebimento da notícia, os pais passam a se preocupar com uma série de fatores objetivos e subjetivos que vão desde o prosseguimento ou não da gestação até qual será o futuro da filha e da criança.

Neste estudo, foi possível observar que os pais das adolescentes sentem que precisam cuidar da filha e opinar sobre diversos aspectos que envolvem a gravidez e projetos de vida futuros da jovem. Este envolvimento dos pais é importante, especialmente quando ele auxilia a jovem mãe a se organizar frente à experiência de gestação e aos projetos de vida futuros (casamento, estudos, trabalho). Contudo, se excessivo, esse envolvimento paterno pode não contribuir para que a jovem e seu companheiro vivenciem algumas experiências importantes e possam assumir responsabilidades que essa nova situação implica.

Dellmann-Jenkins e Colaboradores (1993) indicam que o apoio familiar é um fator importante na determinação das experiências de maternidade. $\mathrm{O}$ apoio fornecido auxilia a adolescente no cumprimento de muitas de suas tarefas, como nos cuidados da criança, o que lhe possibilita continuar a educação formal ou a preparação para o trabalho. Contudo, esse auxílio pode se tornar uma situação de conflito. É o caso quando mães de jovens adolescentes desqualificam os esforços da filha em assumir os cuidados pelo bebê, discordando ou criticando as técnicas de maternagem da filha. 
A perspectiva dos pais diante da gestação na adolescência

A.C.G. Dias, N.D. Patias, M.R. Gabriel \& M.A.P. Teixeira

Os pais podem, também, ao tomar para si tarefas que seriam da adolescente, deixá-la sem espaço para exercer o papel de mãe e desenvolver a competência que resulta da própria vivência desse papel. Essa interferência dos pais pode ser entendida como uma tentativa de ajudar a filha, que é vista como imatura para tomar conta de uma criança e das responsabilidades que lhes são exigidas. Para os pais restam poucas alternativas, já que a gravidez da filha adolescente é, na maioria das vezes, algo novo para eles também, sendo que esse fenômeno interfere nas expectativas que os mesmos possuem a respeito do futuro das filhas. Neste sentido, tanto as jovens como seus pais necessitam de apoio para vivenciar tanto a gravidez como os momentos iniciais de cuidado do bebê.

\section{Referências bibliográficas}

ARCANJO, C.M.; DE OLIVEIRA, M.I.V. \& BEZERRA, M.G.A. Gravidez em adolescentes de uma unidade municipal de saúde em Fortaleza - Ceará. Escola Anna Nery Revista de Enfermagem, 11(3): 445-51, 2007.

ARIÈS, p. História social da criança e da família. $2^{\text {a }}$ edição. Rio de Janeiro: LTC, 1981.

BADINTER, E. Um amor conquistado: o mito do amor materno. Rio de Janeiro: Nova Fronteira, 1985.

ABLAMOWICZ, H. Shame as an interpersonal dimension of communication among doctoral students: an empirical phenomenological study. Journal on Phenomenological Psychology, 23(1): 30-49, 1992.

BLACK, M.M.; PAPAS, M.A.; HUSSEY, J.M.; DUBOWITZ, H.; KOTCH, J.B.; ENGLISH, D. \& SCHNEIDER, M. Behavior and development of preschool children born to adolescent mothers: risk and 3-generation households. Pediatrics, 109(4): 573-80, 2002.

BLOOM, K.C. Perceived relationship with father of the baby and maternal attachment in adolescents. Journal of Obstetric Gynecology Neonatal Nursing, 27: 420-30, 1998.

BOCK, A. A adolescência como construção social: estudo sobre livros destinados a pais e educadores. Revista Semestral da Associação Brasileira de Psicologia Escolar e Educacional (ABRAPEE), 11(1): 63-76, 2007.

BOEMER, M.R. \& MARIUTTI, M.G. A mulher em situação de abortamento: um enfoque existencial. Revista da Escola de Enfermagem da USP, 37(2): 59-71, 2003. 
BORSA, J. \& NUNES, M.L. Aspectos psicossociais da parentalidade: o papel de homens e mulheres na família nuclear. Psicologia Argumento, 29(64): 3139, 2011.

BRASIL, Ministério da Saúde. Secretaria Executiva. Coordenação da Saúde da Criança e do Adolescente. Programa Saúde do Adolescente. Bases Programáticas. 2 ${ }^{a}$ Edição, p. 32. Brasília; Ministério da Saúde, 1996.

CERVENY, C.M.O. \& BERTHOUD, C.M.E. Ciclo vital da família brasileira. In: L.C. OSÓRIO \& M.E. VALE (Orgs). Manual de terapia familiar. p. 2537. Porto Alegre: Artmed, 2009.

CHALEM, E.; MITSUHIRO, S.S.; FERRI, C.p.; BARROS, M.C.M.; GUINSBURG, R. \& LARANJEIRA, R. Gravidez na adolescência: perfil sócio-demográfico e comportamental de uma população da periferia de São Paulo, Brasil. Cadernos de Saúde Pública, 23(1): 177-86, 2007.

CORREIA, D.S.; CAVALCANTE, J.C.; EGITO, E.S. \& MAIA, E.M. Prática do abortamento entre adolescentes: Um estudo em dez escolas de Maceió (AL, Brasil). Ciência \& Saúde Coletiva, 16(5): 2469-76, 2011.

DIAS, A.C. \& TEIXEIRA, M.A. Gravidez na adolescência: um olhar sobre um fenômeno complexo. Paidéia, Ribeirão Preto, 45(2): 123-31, 2010.

DIAS, A.C.G.; PATIAS, N.D.; FIORIN, P.C. \& DELATORRE, M.Z. O significado da maternidade na adolescência para jovens gestantes. Revista Brasileira de História \& Ciências Sociais, 3(6): 153-67, 2011.

ESTEVES, J.R. \& MENANDRO, P.R.M. Trajetórias de vida: repercussões da maternidade adolescente na biografia de mulheres que viveram tal experiência. Estudos de Psicologia, 10(3): 363-70, 2005.

FALCÃO, D.V.S. \& SALOMÃO, N.M.R. O papel dos avós na maternidade adolescente. Estudos de Psicologia, 22(2): 205-12, 2005.

FREITAS, G.V.S. \& BOTEGA, N.J. Gravidez na Adolescência: prevalência de depressão, ansiedade e ideação suicida. Revista da Associação Médica Brasileira, 48(3): 245-49, 2002.

FONSECA, A.L.B. Práticas educativas no contexto das mães adolescentes. Dissertação de mestrado. Salvador: Universidade Federal da Bahia, 2000.

GAMA, S.G.N.; SZWARCWALD, C.L. \& LEAL, M.C. Experiência de gravidez na adolescência, fatores associados e resultados perinatais entre puérperas de baixa renda. Cadernos de Saúde Pública, 18(1): 153-61, 2002. 
A perspectiva dos pais diante da gestação na adolescência

A.C.G. Dias, N.D. Patias, M.R. Gabriel \& M.A.P. Teixeira

GODINHO, R.A.; SCHELP, J.R.B.; PARADA, C.M.G. DE L. \& BERTONCELLO, N.M.F. Adolescentes e grávidas: onde buscam apoio? Revista Latino-Americana de Enfermagem, 8(2): 25-32, 2000.

GONÇALVEZ, S.D.; PARADA, C.M.G.L. \& BERTONCELLO, N.M.F. Percepção de mães adolescentes acerca da participação paterna na gravidez , nascimento e criação do filho. Revista da Escola de Enfermagem da USP, 35(4): 406-12, 2001.

HOGA, L.A.K.; BORGES, A. \& ALVAREZ, R. Gravidez na adolescência: valores e reações dos membros da família. Acta Paulista de Enfermagem, 22(6): 779-85, 2009.

HOGA, L.A.K.; BORGES, A.L.V. \& REBERTE, L.M. Razões e reflexos da gravidez na adolescência: narrativas dos membros da família. Escola Anna Nery Revista de Enfermagem, 14(1): 151-57, 2010.

LEVANDOWSKI, D.C.; PICCININI, C.A. \& LOPES, R.C. Maternidade adolescente. Estudos de Psicologia (Campinas), 25(2): 251-63, 2008.

LIMA C.T.B.; FELICIANO, K.V. DE O.; CARVALHO, M.F.S.; SOUZA, A.P.P.; MENABÓ, J.B.C.; RAMOS, L.S.; CASSUNDÉ, L.F. \& KOVÁCS, M.H. Percepções e práticas de adolescentes grávidas e de familiares em relação à gestação. Revista Brasileira de Saúde Materno-Infantil, 4(1): 71-83, 2004.

MADI, J.M.; BERTOTTO, M.S. \& RIBEIRO, E. Aspectos observados na gravidez da adolescente: identificação de algumas características de importância epidemiológica. Revista Científica da AMECS, 10(1): 1-6, 2001.

PERES, S.O. \& HEILBORN, M.L. Cogitação e prática do aborto entre jovens em contexto de interdição legal: o avesso da gravidez na adolescência. Cadernos de Saúde Pública, 22(7): 1411-20, 2006.

PRETO, N.G. Transformação do Sistema Familiar na Adolescência. In: B. CARTER \& M. McGOLDRICK (Orgs). As mudanças no ciclo de vida familiar: uma estrutura para a terapia familiar. p. 185-205. Porto Alegre: Artmed, 1995.

SILVA, D.V.\& SALOMÃO, N.M.R. A maternidade na perspectiva de mães adolescentes e avós maternas dos bebês. Estudos de Psicologia, 8(1): 13545, 2003.

SILVA, L. \& TONETE, V.L.p. A gravidez na adolescência sob a perspectiva dos familiares: compartilhando projetos de vida e cuidado. Revista Latino-americana de Enfermagem, 14(2): 199-206, 2006. 


\section{HUMANAS}

STEINBERG, L. \& SILK, J. Parenting Adolescents. In: M. Bornstein (Ed.). Handbook of Parenting: Children and Parenting. p. 103-26. New Jersey: Lawrence Erlbaum Associates Publishers, 2002.

UNGER, D.G. \& COOLEY, R. Partner and grandmother contact in black and white teen parent families. Journal of Adolescent Health, 13: 546-52, 1992.

WAGNER, A.; PREDEBON, J. \& FALCKE, D. Transgeracionalidade e educação: como se perpetua a família? In: A. WAGNER (Org). Como se perpetua a família? A transmissão dos modelos familiares. p. 93-105. Porto Alegre: EDIPUCRS, 2005.

YAZLLE, M.E.H.D.; MENDES, M.C.; PATTA, M.C.; ROCHA, J.S.Y.; AZEVEDO, G.D. \& MARCOLIN, A.C. A adolescente grávida: alguns indicadores sociais. Revista Brasileira de Ginecologia e Obstetrícia, 24(9): 609-14, 2002. 